\title{
Promotion of pseudomycelium formation of Candida albicans in culture: a morphological study of the effects of miconazole and ketoconazole
}

\author{
M. BORGERS \\ D.Sc. \\ H. VAN DEN BOSSCHE
}

M. De BRABANDER

D.Sc.

J. VAN CUTSEM

\author{
Janssen Pharmaceutica, Research Laboratories, B-2340 Beerse, Belgium
}

\begin{abstract}
Summary
The effects of miconazole and its new derivative ketoconazole on Candida albicans have been evaluated by light and electron microscopy.

The growth characteristics and morphology of C. albicans in culture for various periods of time in a solution consisting of Eagle's minimum essential medium supplemented with amino acids and fetal calf serum are emphasized. This medium, normally used for culturing mammalian cells, promotes a rather fast growth of $\boldsymbol{C}$. albicans and favours the development of pseudomycelium. The obvious interest in using such culture conditions for drug evaluation is the prevalence of pseudomycelium, which in vivo is the predominant pathological form of $C$. albicans. Suppression of pseudomycelium formation is found in the $10^{-9}$ to $10^{-7} M$ concentration range of the imidazoles. Growth retardation and the destruction of both yeast and pseudomycelial forms brought about by incubating the cells with $10^{-9}$ to $10^{-4} \mathrm{M}$ of the drugs are reported. At low doses these changes include the alteration of cell division, an increase in cell volume and a progressive deterioration of subcellular organelles at the cell periphery. At higher doses the involvement of all other organelles is observed finally leading to complete cell necrosis.
\end{abstract}

\section{Introduction}

Existing in vitro culture models in which the effects of antifungal drugs have been evaluated on Candida albicans apply almost entirely to the yeast form of this species. The prevailing form found in infectious diseases of $C$. albicans, however, is the pseudomycelial form. Hence, the availability of cultures in which pseudomycelium predominates would be of considerable interest. They not only mimic the clinical picture better, but also open the way to several new experimental approaches in relation to drug application

In this respect, the following drug effects can be evaluated in a situation which is free from host interference: (1) the minimal concentration that inhibits outgrowth of pseudomycelium from the inoculated yeast form as assessed by light microscopy; (2) the dose-related effects on growth and morphological, biochemical and cytochemical characteristics; (3) the effects of drugs on already established pseudomycelia. The latter makes it possible to differentiate fungistatic and fungicidal properties of the compounds on the vegetative form; (4) the effect of serum on drug activity; (5) the differential toxicity of drugs on mammalian cells and C. albicans in mixed cultures.

This paper deals with a first series of experiments on $C$. albicans, cultured in a pseudomyceliumpromoting medium. The effects of different doses of miconazole and its newly synthetized analogue ketoconazole (cis-1-acetyl-4-[4- \{[2-(2,4-dichlorophenyl)2-(1H-imidazol-1-ylmethyl)-1,3-dioxolan-4-yl]methoxy\} phenyl]piperazine) are evaluated by light and electron microscopy. Ketoconazole has recently proved to be an antifungal agent with oral activity against a broad range of yeasts and fungi (Thienpont et al., 1979).

\section{Materials and methods}

C. albicans, strain B 12377 was maintained on Sabouraud agar slants at $25^{\circ} \mathrm{C}$. Yeast cells were grown at $37^{\circ} \mathrm{C}$ on Sabouraud agar and a loopful from a $24 \mathrm{hr}$ 's slant was inoculated in $4.5 \mathrm{ml}$ of Sabouraud broth and cultured at $37^{\circ} \mathrm{C}$ for $24 \mathrm{hr}$. A $0.5-\mathrm{ml}$ aliquot of this culture was inoculated in $100 \mathrm{ml}$ of a casein hydrolysate yeast extract glucose medium (CYG medium). Cells were grown at $37^{\circ} \mathrm{C}$ aerobically in a reciprocating shaker for $64 \mathrm{hr}$. From this culture a $0 \cdot 2-\mathrm{ml}$ aliquot was again inoculated in $100 \mathrm{ml} \mathrm{CYG}$ medium and grown for another $24 \mathrm{hr}$ at $37^{\circ} \mathrm{C}$ while shaking (Van den Bossche et al., 1978). The aim of this procedure was to prepare the cells in a standardized way, before inoculating the experimental media.

The pseudomycelium growth-promoting medium 
consisted of Eagle's minimal essential medium (Flow Laboratories) supplemented with non-essential amino acids (Flow), $10 \%$ fetal calf serum and sodium bicarbonate $2 \mathrm{~g} / \mathrm{l}$. Yeast cells were seeded at densities of $1.5 \times 10^{5} / \mathrm{ml}$ or $1.5 \times 10^{4} / \mathrm{ml}$ in sterile Petri dishes (diameter $9 \mathrm{~cm}$ ) containing $10 \mathrm{ml}$ of medium. Cells were grown in a humidified atmosphere of $5 \%$ $\mathrm{CO}_{2}$ in air at $37^{\circ} \mathrm{C}$.

The effects of miconazole and ketoconazole were evaluated in 2 experimental conditions. In a first series the compounds were added immediately after inoculation of the yeast cells in order to study the effects on the formation of pseudomycelium and the morphology of the yeast and pseudomycelial cells. In a second series, the compounds were added after $24 \mathrm{hr}$ of growth when pseudomycelium was fully developed and yeast forms were almost totally lacking. In both experiments the cultures were exposed to miconazole and ketoconazole in doses ranging from $10^{-9} \mathrm{M}( \pm 0.5 \mathrm{ng} / \mathrm{ml})$ to $10^{-4} \mathrm{M}( \pm 50$ $\mu \mathrm{g} / \mathrm{ml})$. The solvent for miconazole was dimethylsulphoxide (final concentration $0.5 \%$ ); ketoconazole was added as an aqueous solution. Pseudomycelium development was observed by light microscopy at various periods after inoculation. Transmission and scanning electron microscopy of the cultures was performed after $24 \mathrm{hr}$ of exposure to the drugs. After harvesting, cells of both experiments were pelleted, fixed and prepared for electron microscopy as described by Borgers and De Nollin (1974).

\section{Results \\ Development and growth of pseudomycelium}

The inoculated yeast cells went through a very short lag phase and within one hour they had formed germ tubes. Branching hyphae occurred after $4 \mathrm{hr}$ of inoculation and mycelial colonies could be observed from $8 \mathrm{hr}$ onwards. They continued to grow without signs of cellular necrosis until $48 \mathrm{hr}$ after inoculation.

\section{Light and electron microscopic assessment of pseudo- mycelium inhibition}

When the drugs were simultaneously added with the inoculum, ketoconazole completely inhibited the formation of pseudomycelial outgrowth from the inoculated yeast at $10^{-8} \mathrm{M}(5 \cdot 3 \mathrm{ng} / \mathrm{ml})$ whereas miconazole had the same effect at $10^{-6} \mathrm{M}(0.48 \mu \mathrm{g} / \mathrm{ml})$.

In the scanning electron microscope the first prominent changes were seen with $10^{-9} \mathrm{M}$ ketoconazole and $10^{-8} \mathrm{M}$ miconazole. At variance with control cultures which almost exclusively contain very long pseudohyphae (Fig. 1), such treated cultures showed predominantly short pseudohyphae (approx. $10 \%$ of the control length) (Fig. 2). At $10^{-8} \mathrm{M}$ ketoconazole (Fig. 3) and $10^{-6} \mathrm{M}$ miconazole short germ tubes became rare and abnormal configurations were observed at sites of attempted budding. Such structures were usually swollen (diameter $4 \mu \mathrm{m}$ ) and protruded from abnormally swollen and scarred yeasts. Practically all cells $(>99 \%$ ) were yeast forms, most of them clustered and of heterogeneous size (diameter $2-5 \mu \mathrm{m}$ ). Surface irregularities were more pronounced after exposure to the drugs at concentrations up to $10^{-5} \mathrm{M}$ and many cells then had a diameter of 5-7 $\mu \mathrm{m}$. With $10^{-4} \mathrm{M}$ ketoconazole, most of the cells were smooth surfaced and only a few were swollen. On the contrary, with $10^{-4} \mathrm{M}$ miconazole, many of the remaining cells were irregularly contoured and angular in shape, and possessed multiple bud scars or scars of attempted budding.

With transmission electron microscopy no differences were seen in the ultrastructure of subcellular organelles from pseudomycelium of control cultures and those after treatment with $10^{-9} \mathrm{M}$ ketoconazole or $10^{-8} \mathrm{M}$ and $10^{-7} \mathrm{M}$ miconazole. The ultrastructure details of pseudomycelium were equally well preserved as those of the yeast cells reported in earlier studies (Borgers and De Nollin, 1974). At both seeding densities all cells were viable after $24 \mathrm{hr}$ of growth in the control cultures. The lowest doses that completely inhibited pseudomycelial outgrowtlo $\left(10^{-8} \mathrm{M}\right.$ for ketoconazole and $10^{-6} \mathrm{M}$ for miconazole also produced the earliest alterations on the $C . a l b i$ cans yeast form. These changes mainly consisted is an increase in volume, caused partially by hyper 8 trophy of the cytoplasm and partially by the cons siderable thickening of the cell wall, and in the deposition of osmiophilic material, possibly altere phospholipids, at the cell wall. Cell necrosis was rare with these doses, but became gradually more obvious with ketoconazole from $10^{-7} \mathrm{M}$ onwards and with miconazole from $10^{-5} \mathrm{M}$ onwards. Swollen cells with multiple bud scars were numerous and had a very thick wall in which many phospholipid-like vesicles and whorls settled. It was most unusual that the ketoconazole-treated cells and to a lesser extent the miconazole-treated ones contained abundant lipid globules and some of them membraneassociated needle-like crystals. At the $10^{-4} \mathrm{M}$ concentration, most cells of the ketoconazole cultures appeared to be completely necrotic and were filled with lipid globules. With miconazole, a great number of cells were lysed in which the organelles were only just recognizable but a large portion showed lesions comparable to the $10^{-5} \mathrm{M}$-treated cells.

\section{Effects of the drugs on the morphology of outgrown} pseudomycelium

In this series of experiments the inoculated yeast cells were grown for $24 \mathrm{hr}$ to develop into pseudomycelia and were then exposed to the drugs for another $24 \mathrm{hr}$. After $48 \mathrm{hr}$ of growth the control 

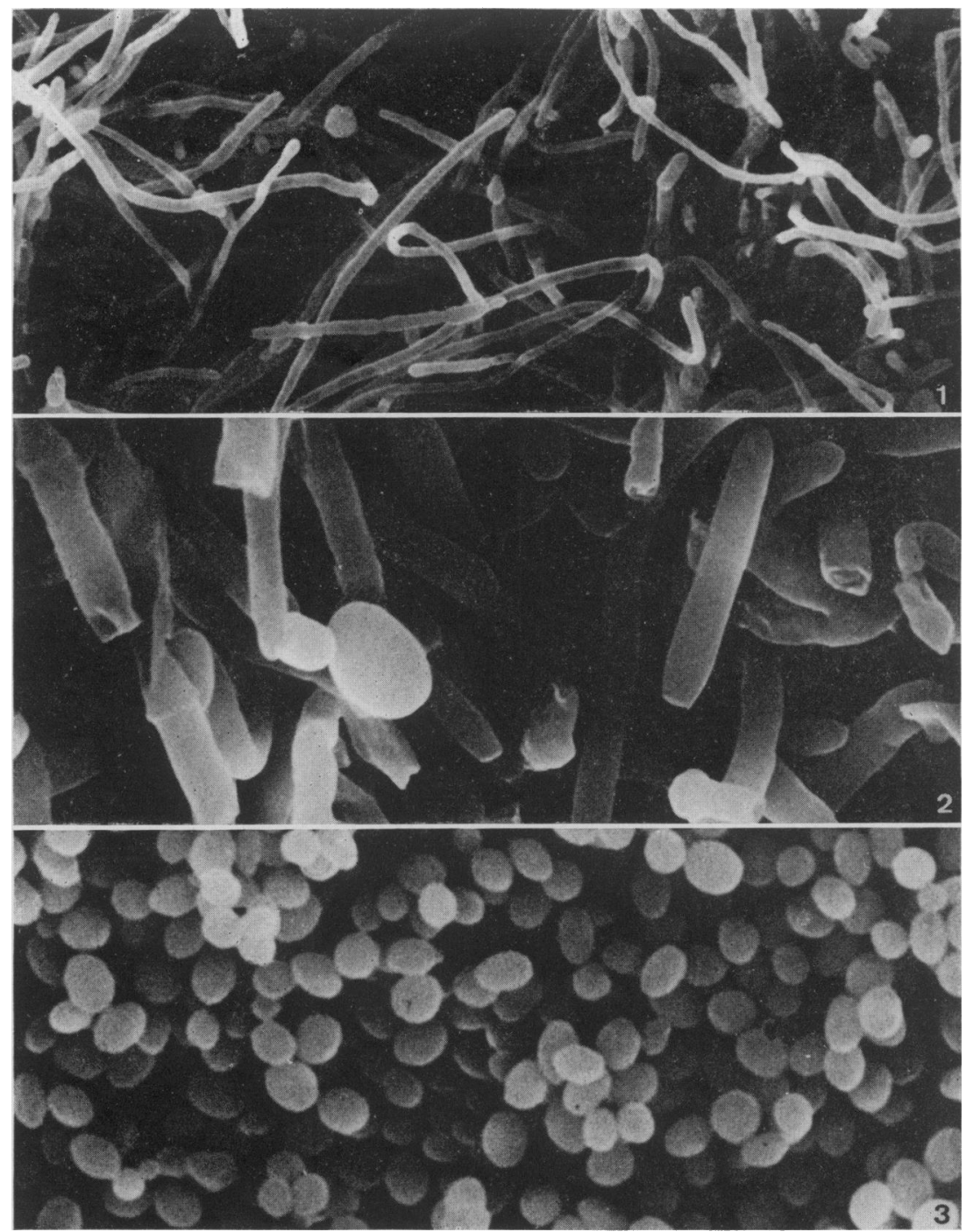

FIGS 1-3. Scanning electron micrographs.

1. Control culture of $C$. albicans grown for $24 \mathrm{hr}$ in the pseudomycelium-promoting medium. Practically all cells consist of long, branching hyphae $(\times 720)$

2. Culture exposed to $10^{-8} \mathrm{M}(4 \cdot 8 \mathrm{ng} / \mathrm{ml})$ miconazole for $24 \mathrm{hr}$. The culture consists of short non-branching pseudomycelial elements and few yeast cells $(\times 2800)$

3. Culture exposed to $10^{-8} \mathrm{M}(5 \cdot 3 \mathrm{ng} / \mathrm{ml})$ ketoconazole for $24 \mathrm{hr}$. Practically all cells are in the yeast form, germ tubes are rare and no branching hyphae are noted $(\times 1210)$

cultures showed well developed pseudomycelia (Fig. 4) which were all viable when cell density at seeding was kept at $1.5 \times 10^{4}$ cells $/ \mathrm{ml}$. Miconazole at $10^{-8}$ to $10^{-7} \mathrm{M}$ and ketoconazole at $10^{-9} \mathrm{M}$ did not provoke morphologically detectable changes when added after $24 \mathrm{hr}$ of inoculation. Very thick walled yeast-type cells which were sometimes elongated, showed osmiophilic deposits after $10^{-6} \mathrm{M}$ miconazole and $10^{-8} \mathrm{M}$ ketoconazole. They were most probably derived from the tips of pseudomycelium which, under the influence of the drugs, were no longer able to produce hyphae but instead allowed the outgrowth of altered yeast forms. Such cells became more abundant at $10^{-5} \mathrm{M}$ miconazole and $10^{-6} \mathrm{M}$ ketoconazole. These doses equally produced proliferation of unusually large peroxisomes in 
yeasttype cells. Enlarged peroxisomes were not seen pseudomycelium. At concentrations $\geqslant 10^{-5} \mathrm{M}$, both in drugs induced necrosis of outgrown pseudomycelium. The necrotized cells always possessed a more or less intact cell wall without osmiophilic inclusions. At the $10^{-4} \mathrm{M}$ concentration, miconazole appeared to be at least as toxic to outgrown pseudomycelia as ketoconazole (Figs 5 and 6).
Scanning electron microscopy has confirmed these structural alterations as far as transformation of hyphae to abnormal yeast forms is concerned. When doses were applied in a range that still allowed retarded but continuous growth $\left(10^{-9} \mathrm{M}\right.$ to $10^{-6} \mathrm{M}$ of both drugs) a dose-dependent return to the yeast form was seen. Such yeasts were voluminous and irregularly surfaced. Although transmission electron

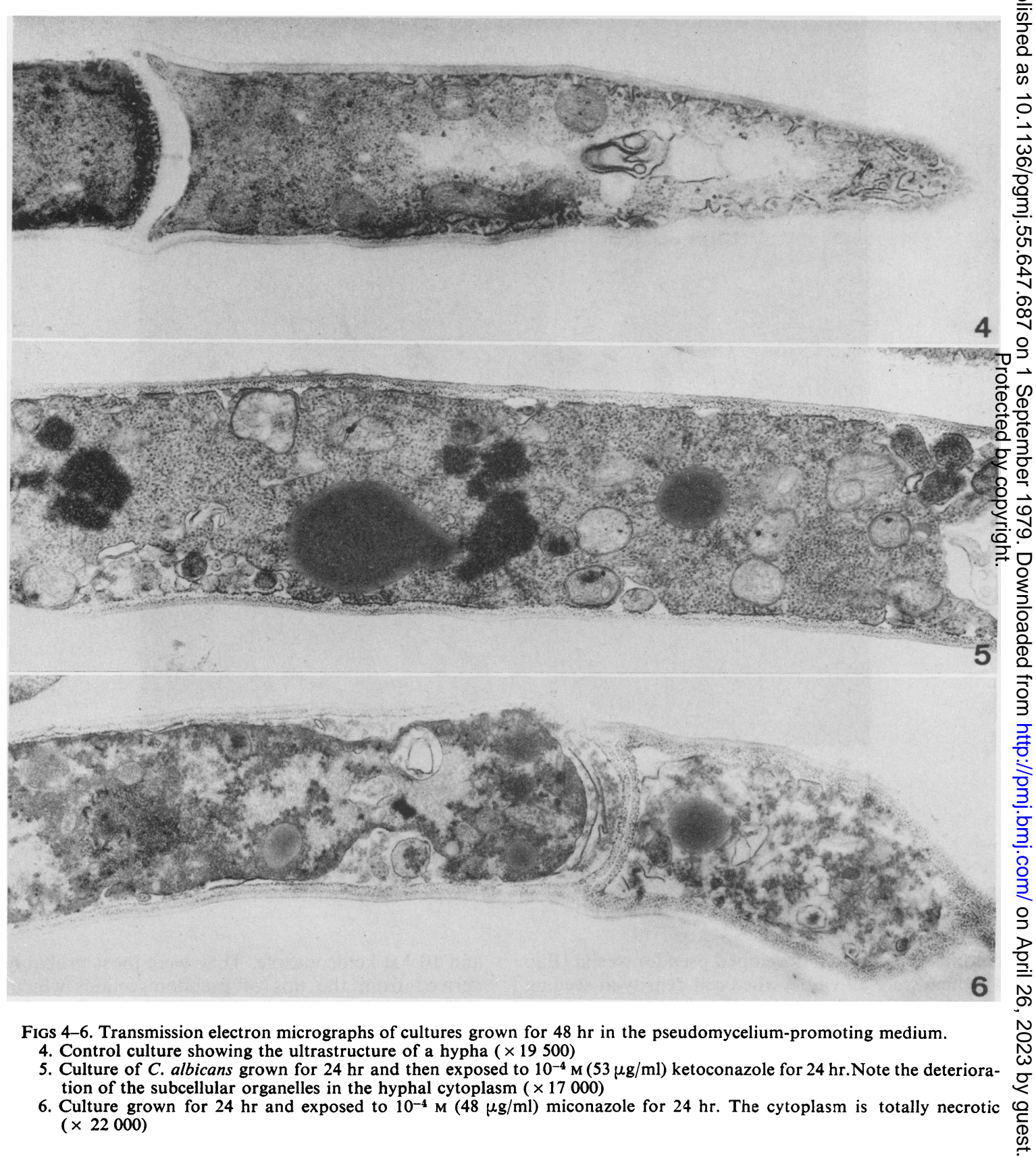


microscopy revealed that from $10^{-5} \mathrm{M}$ onwards many of the outgrown pseudomycelia were necrotic, their surface morphology in the scanning microscope appeared to be normal.

\section{Discussion}

Although pseudomycelium is the predominating form in candidiasis, practically all in vitro studies involved with the evaluation of antifungal drugs on C. albicans have been performed on the yeast form. These include the determination of the minimal inhibitory and the fungicidal concentration and studies on the mechanism of action and drug resistance. This is mainly because of the lack of suitable conditions for inducing and maintaining pure pseudomycelial development in culture. A few years ago, Lee, Buckley and Campbell (1975) succeeded in producing purely mycelial phase cells cultivated in a liquid synthetic medium. However, the transformation was transitory so that the cultures only contained pure pseudomycelium between 18 and $27 \mathrm{hr}$ after inoculation. A long-lasting viable culture of pseudomycelium, closely resembling the form found in many superficial and systemic infections, is needed clearly to evaluate the efficacy of drugs on this phase of $C$. albicans. Such conditions were produced in the present study and offer the possibility of experimental approaches that may contribute to the understanding of pathogenicity and therapy of this form. First of all, the presence of serum which definitely favours this long-lasting pseudomycelial growth makes it likely the better to mimic the in vivo situation. Secondly, since this medium is a normal growth-supporting medium for mammalian cells, the interaction between host and invasive cells can be studied.

The present results of the simultaneous exposure of inoculated cells to miconazole and ketoconazole for $24 \mathrm{hr}$ reveal that ketoconazole is about 100 times more potent in inhibiting pseudomycelium formation and provoking subcellular changes than miconazole under the same conditions. This is at variance with the effects of these drugs on C. albicans cultured in common yeast-promoting media. In an earlier report, Van den Bossche, Willemsens and Cornelissen (1977) described the differential sensitivity towards drugs as being strongly dependent on growth conditions. Furthermore, Van Cutsem et al. (unpublished results) found that the addition of bovine serum to Sabouraud culture medium changes the effects of ketoconazole and miconazole.

In contrast to studies based on the yeast form of C. albicans when the drug is added to well developed and still growing pseudomycelium (a situation very much resembling that when a curative treatment is imposed) electron microscopy confirms the high potency of both miconazole and ketoconazole in killing an existing pseudomycelium. The morphological observations presented accord with previous ultrastructural findings (De Nollin and Borgers, 1974) and concern the sequential and dosedependent changes at the cell periphery, the increase in cell volume, the increase in the number of peroxisomes, the deterioration of the substructural organelles such as nuclei, mitochondria and the vacuolar system, fatty degeneration of the cytoplasm and, finally, plasmolysis.

Although this first series of experiments on pseudomycelium cultures of $C$. albicans gives a reasonable impression of what can be achieved with this in vitro model, more information is needed from exposing cultures to antifungals at different phases of growth for longer periods of time and thereby imitating even more closely the usual treatment schedule as applied in C. albicans infections. As well as evaluating its activity on the more conventional yeast forms, assessing the effect of a drug on pseudomycelium enables one to differentiate between one which is a true fungicide and one which is merely fungistatic.

\section{Acknowledgments}

The authors wish to thank Dr D. Thienpont for his constructive comments in the preparation of this manuscript; M. Van de Ven, S. Willemsens and L. Leyssen for preparing the cultures and the micrographs; $\mathrm{H}$. Vanhove for reviewing the manuscript; and A. Van der Eycken for typing the manuscript.

This work is partly supported by a grant from the I.W.O.N.L. (Instituut tot Aanmoediging van het Wetenschappelijk Onderzoek in Nijverheid en Landbouw) Belgium.

\section{References}

Borgers, M. \& DE Nollin, S. (1974) The preservation of subcellular organelles of Candida albicans with conventional fixatives. Journal of Cell Biology, 62, 574.

DE Nollin, S. \& Borgers, M. (1974) The ultrastructure of Candida albicans after in vitro treatment with miconazole. Sabouraudia, 12, 341.

Lee, K.L., Buckley, H.R. \& Campbell, C. (1975) An amino acid synthetic medium for the development of mycelia and yeast forms of Candida albicans. Sabouraudia, 13, 148.

ThienPont, D., VAn Cutsem, J., VAN Gerven, F. \& JansSen, P.A.J. (1979) Ketoconazole - A broad spectrum orally active antimycotic. Experientia, 35, 606.

Van den Bossche, H., Willemsems, G., Cools, W., LAuWers, W.F.J. \& Le Jeune, L. (1978) Biochemical effects of miconazole on fungi. II. Inhibition of ergosterol biosynthesis. In: Candida albicans. Chemicobiological Interactions, 21, 59.

Van den Bossche, H., Willemsens, G. \& Cornelissen, F. (1977) The in vitro action of $R 41400$ and miconazole nitrate on the growth of Candida albicans. Janssen Pharmaceutica, Preclinical Research Report, R 41 400/8, acc. No. 13373. 